\title{
Acoustic analysis of snoring sound in patients with simple snor- ing and obstructive sleep apnoea
}

\author{
J.A. Fiz*, J. Abad*, R. Jané**, M. Riera*, M.A. Mañanas**, P. Caminal**, \\ D. Rodenstein+, J. Morera*
}

Acoustic analysis of snoring sound in patients with simple snoring and obstructive sleep apnoea. J.A. Fiz, J. Abad, R. Jané, M. Riera, M.A. Mañanas, P. Caminal, D. Rodenstein, J. Morera. CERS Journals Ltd 1996.

ABSTRACT: Snoring, a symptom which may indicate the presence of the obstructive sleep apnoea syndrome (OSA), is also common in the general population. Recent studies have suggested that the acoustic characteristics of snoring sound may differ between simple snorers and OSA patients. We have studied a small number of patients with simple snoring and OSA, analysing the acoustic characteristics of the snoring sound.

Seventeen male patients, 10 with OSA (apnoea/hypopnoea index (AHI) 26.2 events ${ }^{-1}{ }^{-1}$ ) and seven simple snorers (AHI 3.8 events $^{-} h^{-1}$ ), were studied. Full night polysomnography was performed and the snoring sound power spectrum was analysed.

Spectral analysis of snoring sound showed the existence of two different patterns. The first pattern was characterized by the presence of a fundamental frequency and several harmonics. The second pattern was characterized by a low frequency peak with the sound energy scattered on a narrower band of frequencies, but without clearly identified harmonics. The seven simple snorers and two of the 10 patients with OSA (AIH 13 and 14 events $^{\cdot} h^{-1}$, respectively) showed the first pattern. The rest of the OSA patients showed the second pattern. The peak frequency of snoring was significantly lower in OSA patients, with all but one OSA patient and only one simple snorer showing a peak frequency below $150 \mathrm{~Hz}$

A significant negative correlation was found between AHI and peak and mean frequencies of the snoring power spectrum $(\mathrm{p}<0.0016$ and $\mathrm{p}<0.0089$, respectively).

In conclusion, this study demonstrates significant differences in the sound power spectrum of snoring sound between subjects with simple snoring and obstructive sleep apnoea patients.

Eur Respir J., 1996, 9, 2365-2370.
*Servei de Pneumologia, Hospital Universitario Germans Trias i Pujol, Badalona, Spain. **Instituto de Cibernética (UPC), Barcelona, Spain. ${ }^{+}$Cliniques Universitaires Saint Luc, Université Catholique de Louvain, Brussels, Belgium.

Correspondence: J.A. Fiz

Servei de Pneumologia

Hospital Germans Trias i Pujol

Carretera del Canyet

s/n 08916 Badalona

Barcelona

Spain

Keywords: Acoustic analysis

obstructive sleep apnoea

snore

Received: April 101995

Accepted after revision June 201996

This work was supported by grant $94 / 0625$ FIS (Spain).
In the last 15 yrs, snoring has entered the realm of clinical medicine. Snoring may disturb the social and family life of the snorer, who is unaware that he snores. Snoring is a prevalent symptom, and about $50 \%$ of the adult population snores frequently $[1,2]$. One to five percent of the adult male population suffer from the sleep apnoea syndrome, in which snoring is a dominant symptom. Several treatments exist for simple snoring and for obstructive sleep apnoea (OSA), many of them mutilating or invasive. Recent studies have suggested that the acoustic characteristics of snoring may differ between simple snorers and patients with OSA. Healthy simple snorers, without apnoea episodes, showed a power spectrum of snoring signal with a harmonic structure and a fundamental frequency that ranged 110-190 $\mathrm{Hz}$ [3]. In snoring patients with OSA, frequency components higher than $800 \mathrm{~Hz}$ were found [4].

We have studied a small number of patients with simple snoring or OSA, and analysed the acoustic characteristics of the snoring sound as well as the pattern of respiratory disturbances during sleep.

\section{Material and methods}

Seventeen lifelong nonsmoking male patients from the sleep disorders clinic of the Germans Trias i Pujol hospital in Badalona were studied. Ten of the subjects were diagnosed as having OSA and seven as having simple snoring.

Lung function tests were performed using a spirometer (PFT Horizont System) [5]. Reference values were those of RocA et al. [6]. Arterial blood gas values were measured using a blood gas analyser (Radiometer ABL).

Full night polysomnography was performed according to standard methods [7]. Sleep analysis was performed by visual inspection using RECHTSCHAFFEN and KALES [7] paper scoring. Electroencephalogram (EEG), electro-oculogram (EOG) and chin electromyogram (EMG) were obtained from surface electrodes. Thoracic and abdominal respiratory movements, as well as their sum, were obtained using a inductive plethysmograph (Respitrace NIMS, Miami, USA). Calibration was performed by means of a dry spirometer (S3371; Sensor Medics, 
Anaheim, USA). Arterial oxygen saturation $\left(\mathrm{Sa}_{2} \mathrm{O}_{2}\right)$ was measured using a pulse oximeter (Oxy Shuttle; Sensor Medics, USA) with a finger probe. Oronasal flow was assessed using thermistors. All the signals were recorded on paper using a Sensormedics recorder.

In addition to the above, a miniature microphone (MKE 3010; SennHeiser, Germany) was positioned upon the neck, $1 \mathrm{~cm}$ lateral to the median line at the level of the cricoid cartilage. The microphone was enclosed in a plastic hemisphere, $3 \mathrm{~cm}$ in diameter and leaving a $1 \mathrm{~cm}$ distance between the microphone and the skin, avoiding direct contact with skin surface. The hemisphere was attached to the skin using adhesive tape. The microphone had a flat frequency response between $40 \mathrm{~Hz}$ and $30 \mathrm{kHz}$ (field transmission factor in open loop: $10 \mathrm{mv} \cdot \mathrm{Pa}^{-1} \pm 2.5$ $\mathrm{dB})$.

An apnoea was defined as the absence of airflow during $\geq 10 \mathrm{~s}$. Apnoeas were classified as obstructive or central according to the persistency or absence of respiratory movements, accompanied by a fall in $\mathrm{Sa}_{\mathrm{a}} \mathrm{O}_{2}$ of $\geq 4 \%$. Hypopnoea was defined as a reduction in tidal volume to $\geq 50 \%$ of those recorded during the preceding five breaths for longer than $10 \mathrm{~s}$, accompanied by a fall in $\mathrm{Sa}_{2} \mathrm{O}_{2}$ of $\geq 4 \%$. OSA was defined as the presence of more than 10 apnoeas/hypopnoeas $\cdot \mathrm{h}^{-1}$ of sleep, and the total number of episodes of apnoea and hypopnea per hour of sleep represented the apnoea/hypopnoea index (AHI).

The sound signal was filtered with a band-pass filter between $10 \mathrm{~Hz}$ and $6 \mathrm{kHz}$ (KH 39188). The sound signal together with the flow signal of the thermistor, was stored using a videotape cassette (Racal V Store CH) at a speed of $7.5 \mathrm{in} \cdot \mathrm{s}^{-1}$. Flow and sound signals were processed using a personal computer (PC Compaq desk $368 / 20$ e) with a sampling frequency of $12 \mathrm{kHz}$. Analysis was limited to Stage 1 and 2 non-rapid eye movement (REM) sleep.

Snoring and flow signals were synchronized by means of a digital clock available on videotape recorder. Three episodes of three consecutive breaths with snoring were randomly analysed after identification of 10 periods of snoring. Analysis was performed using the average of the three episodes. In patients with OSA, snoring corresponded to the 1st, 2nd and 3rd breath after an apnoea. Snoring was identified by listening to the sound. Fast Fourier Transform (FFT) was used to calculate sound spectra of the three successive sound inspiratory episodes of snoring. FFT was applied on 1,024 samples. Welch periodogram was applied using a Hanning window with an overlap of $50 \%$.

The following parameters were measured: maximal frequency $\left(f_{\max }\right)$, defined as the upper frequency containing $90 \%$ of the total power of the spectrum; peak frequency $(f$ peak $)$ defined as the frequency with the maximum power; and mean frequency ( $\left.f_{\text {mean }}\right)$ defined as the frequency including half the total power of the spectrum. Harmonics were defined as broad frequency bands in the spectrum analysis $[3,4]$ with a fundamental frequency. For each parameter, the variability was estimated by calculating the coefficient of variation $(\mathrm{CoV})$ individually for each subject or patient. Comparisons were performed using the nonparametric KolmogorovSmirnoff test. Spearman's nonparametric correlation coefficient was used to verify the relationship between sleep parameters with acoustic spectral sound parameters. Results were considered significant if the p-value was lower that 0.05 .

\section{Results}

Table 1 presents the anthropometric as well as the lung function and blood gas values of the patients. Patients with OSA were older, and had somewhat lower values for forced vital capacity (FVC), forced expiratory volume in one second (FEV1) and arterial oxygen tension $\left(\mathrm{Pa}, \mathrm{O}_{2}\right)$ than patients with simple snoring. However, there were no statistically significant differences between groups.

Polysomnographic data are represented in table 2. Sleep architecture was abnormal in both groups, with an excess of Stages 1 and 2 non-REM sleep and very

Table 1. - Anthropometric and respiratory function data of subjects with simple snoring and patients with obstructive sleep apnoea

\begin{tabular}{|c|c|c|}
\hline & Simple snoring & OSA \\
\hline Age yrs & $46 \pm 13$ & $51 \pm 6$ \\
\hline Height $\mathrm{cm}$ & $171 \pm 9$ & $166 \pm 7$ \\
\hline Weight $\mathrm{kg}$ & $87 \pm 22$ & $91 \pm 21$ \\
\hline $\mathrm{BMI} \mathrm{kg} \cdot \mathrm{m}^{-2}$ & $29.7 \pm 7.2$ & $32.9 \pm 7.6$ \\
\hline \multirow{2}{*}{$\begin{array}{ll}\mathrm{FVC} & \mathrm{L} \\
& \% \text { pred }\end{array}$} & $4.4 \pm 1.1$ & $3.5 \pm 0.6$ \\
\hline & $90 \pm 18$ & $83 \pm 13$ \\
\hline \multirow{2}{*}{$\begin{array}{ll}\text { FEV } 1 ~ & \text { L } \\
& \% \text { pred }\end{array}$} & $3.5 \pm 1.1$ & $2.8 \pm 0.7$ \\
\hline & $93 \pm 20$ & $85 \pm 17$ \\
\hline FEV1/FVC \% & $81 \pm 3$ & $78 \pm 8$ \\
\hline \multirow{2}{*}{$\begin{array}{ll}P \mathrm{a}, \mathrm{O}_{2} & \mathrm{kPa} \\
\mathrm{mmHg}\end{array}$} & $12.2 \pm 0.8$ & $10.6 \pm 2.1$ \\
\hline & $91.3 \pm 5.5$ & $79.7 \pm 16.0$ \\
\hline \multirow{2}{*}{$\begin{array}{rl}P_{\mathrm{a}_{1} \mathrm{CO}_{2}} & \mathrm{kPa} \\
& \mathrm{mmHg}\end{array}$} & $5.0 \pm 0.3$ & $5.4 \pm 1.0$ \\
\hline & $37.2 \pm 2.6$ & $40.2 \pm 7.8$ \\
\hline \multirow{2}{*}{$\begin{array}{l}{\mathrm{Sa}, \mathrm{O}_{2}}_{\mathrm{pH}} \% \\
\end{array}$} & $96 \pm 1$ & $94 \pm 6$ \\
\hline & $7.37 \pm 0.0$ & $7.39 \pm 0.0$ \\
\hline
\end{tabular}

Values are presented as mean \pm SD. FVC: forced vital capacity; BMI: body mass index; $\%$ pred: percentage of predicted value; $\mathrm{FEV} 1$ : forced expiratory volume in one second; $\mathrm{Pa}_{\mathrm{a}} \mathrm{O}_{2}$ : arterial oxygen tension; $\mathrm{Pa}_{\mathrm{a}} \mathrm{CO}_{2}$ : arterial carbon dioxide tension; $\mathrm{Sa}_{\mathrm{a}} \mathrm{O}_{2}$ : arterial oxygen saturation.

Table 2. - Sleep parameters of subjects with simple snoring and patients with obstructive sleep apnoea (OSA)

\begin{tabular}{|c|c|c|}
\hline & Simple snoring & OSA \\
\hline TST $\min$ & $268 \pm 66$ & $315 \pm 68$ \\
\hline Awake $\%$ of TST & $23 \pm 13$ & $10 \pm 8 *$ \\
\hline Stage $1 \%$ of TST & $41 \pm 18$ & $28 \pm 17$ \\
\hline Stage $2 \%$ of TST & $28 \pm 18$ & $51 \pm 16$ \\
\hline Stage $3 \& 4 \%$ of TST & $1.3 \pm 3.3$ & $0.3 \pm 0.9$ \\
\hline REM \% of TST & $4.7 \pm 4.6$ & $10.8 \pm 11.7$ \\
\hline Lower $\mathrm{Sa}_{\mathrm{a}, \mathrm{O}_{2}} \%$ & $92 \pm 4$ & $80 \pm 15$ \\
\hline Mean $S_{\mathrm{a}, \mathrm{O}_{2}} \%$ & $95 \pm 2$ & $90 \pm 6$ \\
\hline AHI events $\cdot h^{-1}$ & $3.8 \pm 1.7$ & $26.2 \pm 20.1$ \\
\hline $\begin{array}{l}\text { Maximum duration } \\
\text { of events } \mathrm{s}\end{array}$ & $26.7 \pm 16.5$ & $42.7 \pm 27.3$ \\
\hline $\begin{array}{l}\text { Mean duration } \\
\text { of events } \mathrm{s}\end{array}$ & $17.7 \pm 3.7$ & $20.5 \pm 3.9$ \\
\hline
\end{tabular}

Values are presented as mean \pm SD. TST: total sleep time; REM: rapid eye movement (sleep); $\mathrm{Sa}_{\mathrm{a}} \mathrm{O}_{2}$ : arterial oxygen saturation; AHI: apnoea/hypopnoea index $*$ : $<<0.05$, for comparisons between groups (Kolmogorov-Smirnoff nonparametric test). 


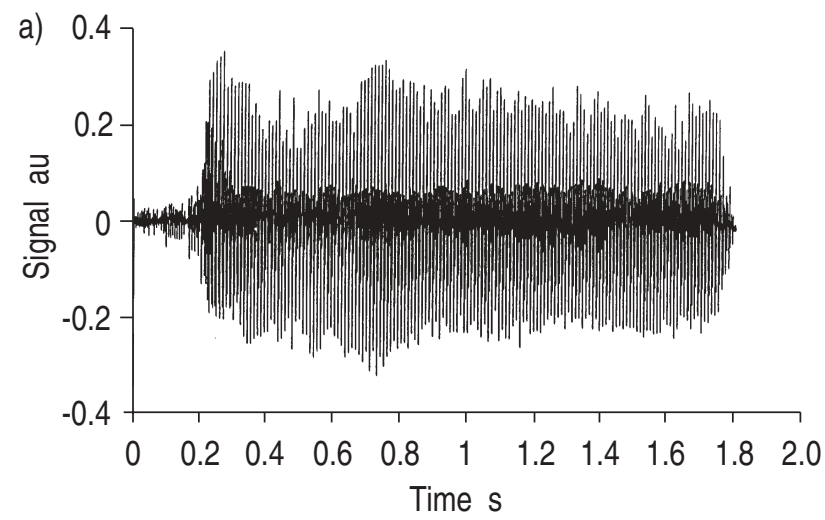

b)
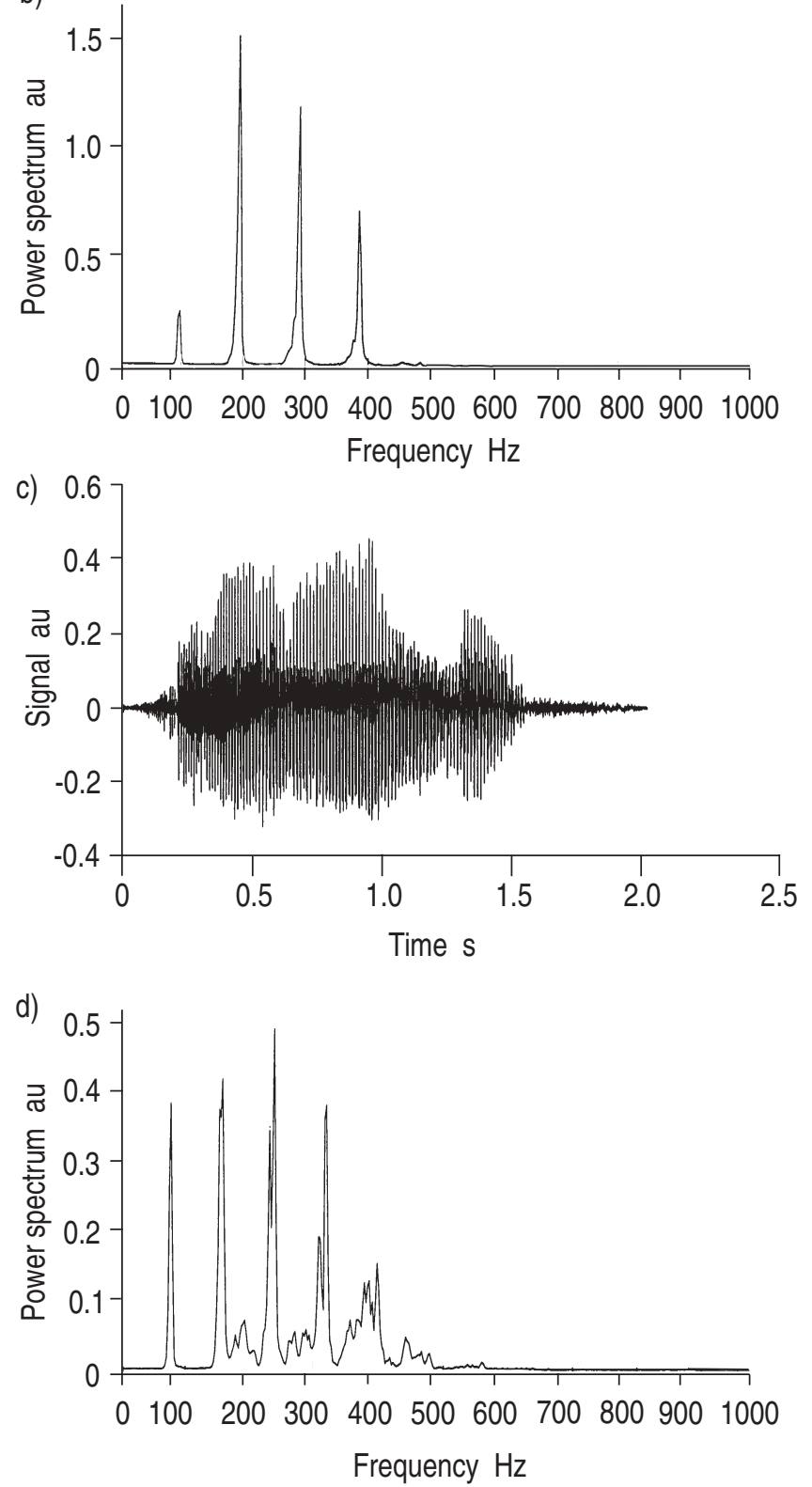

Fig. 1. - Analysis of snoring signal from a simple snorer. a) Signal (arbitrary units $(\mathrm{au})$ ) of first breath; b) power spectrum (au) of first breath; c) signal (au) of second breath; d) power spectrum (au) of second breath. There is a fundamental frequency and clearly identified harmonics.

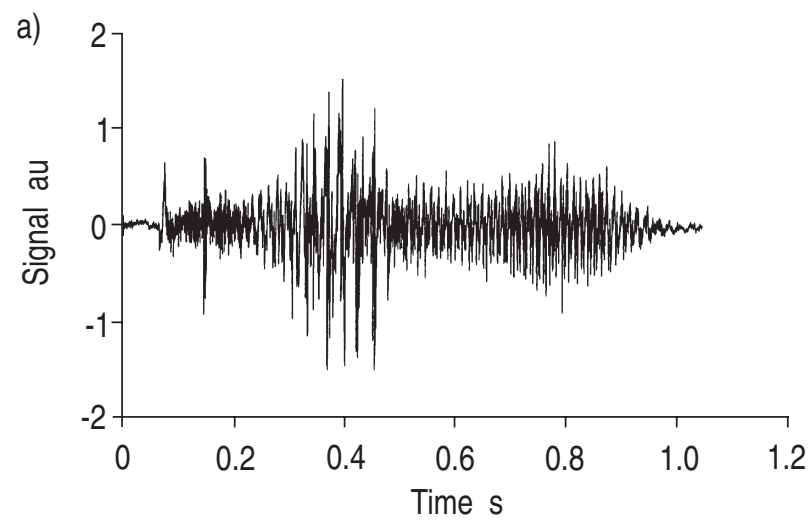

b)

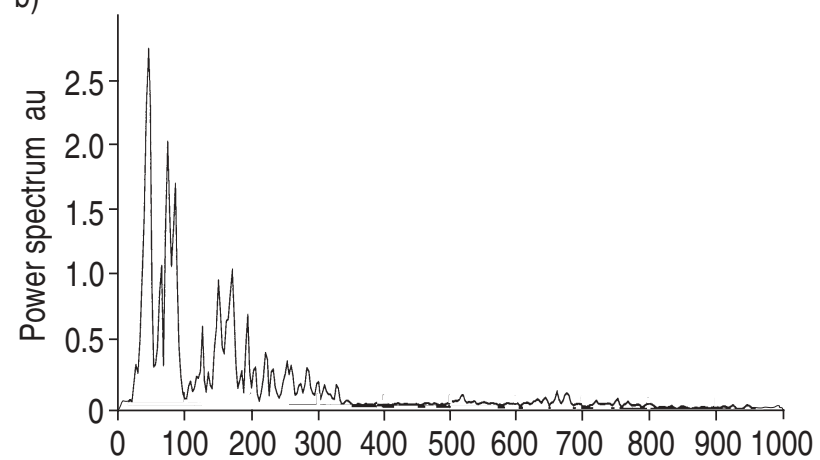

Frequency $\mathrm{Hz}$
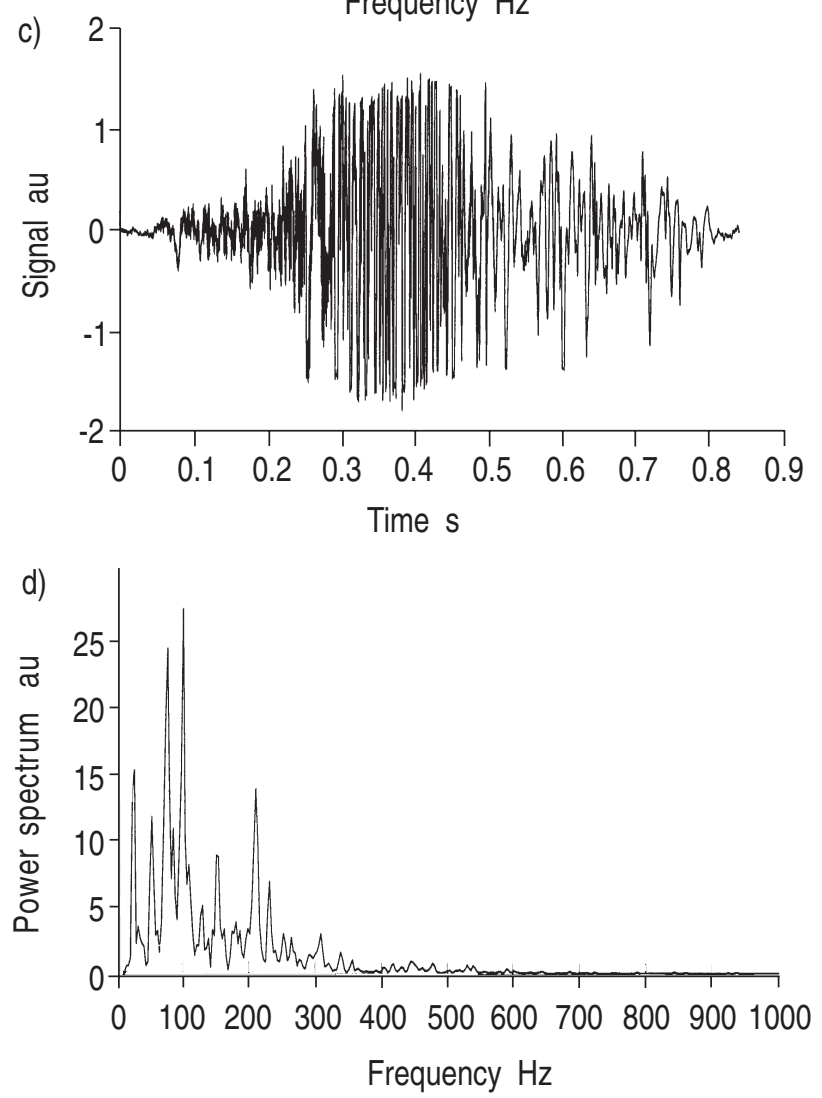

Fig. 2. - Analysis of snoring signal from an obstructive sleep apnoea (OSA) patient. a) Signal (arbitary units (au)) of first postapnoeic snore; b) power spectrum (au) of first postapnoeic snore; c) signal (au) of second postapnoeic snore; d) power spectrum of second postapnoeic snore. Maximum energy is around the fundamental frequency; note that there are no indentifiable harmonics. 
Table 3. - Spectrum frequency parameters of snoring in subjects with or without obstructive sleep apnoea syndrome (OSAS)

\begin{tabular}{llrrr}
\hline & Snorers & $\begin{array}{c}\text { CoV } \\
\%\end{array}$ & OSAS & $\begin{array}{c}\text { CoV } \\
\%\end{array}$ \\
\hline$f_{\text {peak }} \mathrm{Hz}$ & $264 \pm 107$ & 14 & $157 \pm 136$ & 14 \\
$f_{\text {mean }} \mathrm{Hz}$ & $325 \pm 58$ & 15 & $223 \pm 147$ & 16 \\
$f_{\text {max }} \mathrm{Hz}$ & $462 \pm 85$ & 8 & $455 \pm 199$ & 8 \\
\hline
\end{tabular}

Values are presented as mean \pm SD for the relevant data, and mean for the coefficient of variation. $f_{\text {peak: }}$ the frequency with the highest power; $f_{\text {mean: }}$ the frequency with the mean spectrum power; $f_{\max }$ : the frequency with $90 \%$ of total spectrum power; CoV: intrasubject coefficient of variation. *: $\mathrm{p}<0.05$, Kolmogorov-Smirnoff nonparametric test.

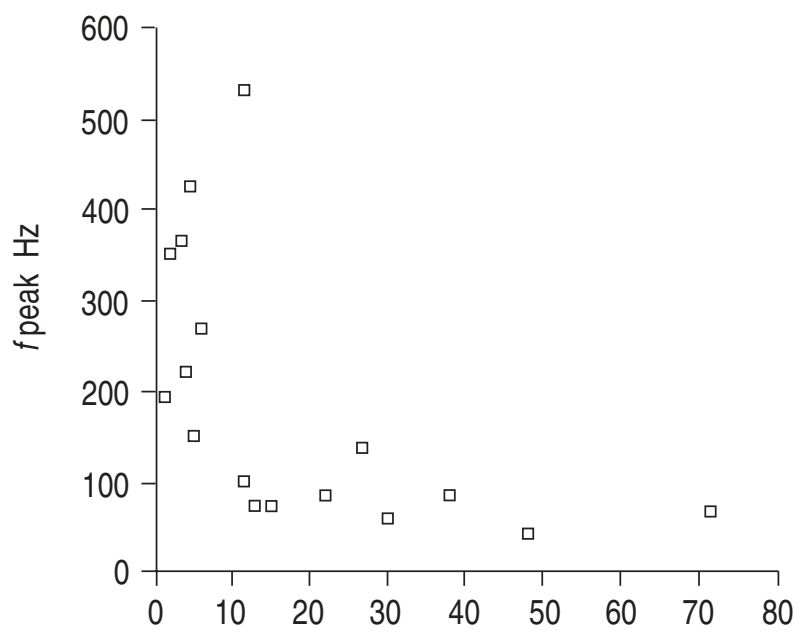

AHI events $\cdot h^{-1}$

Fig. 3. - Relationship between apnoea/hypopnoea index (AHI) and peak frequency $\left(f_{\text {peak }}\right)$ of spectrum in seven simple snorers and 10 obstructive sleep apnoea (OSA) patients. There is a negative relationship. There is a significant negative correlation (Spearman rank order correlation: $\mathrm{r}=-0.70 ; \mathrm{p}<0.0016)$.

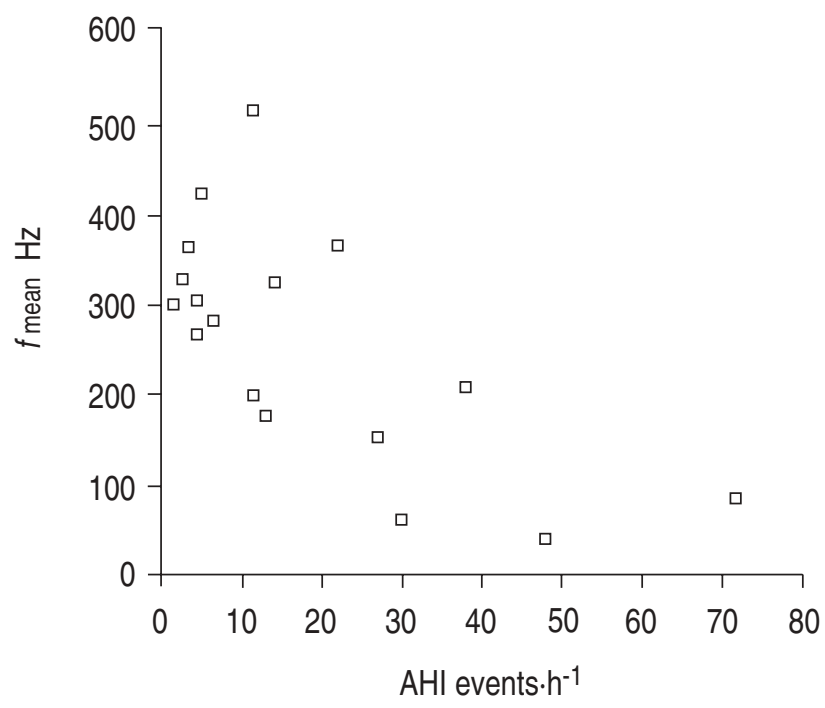

Fig. 4. - Relationship between apnoea/hypopnoea index (AHI) and mean frequency ( $f$ mean) of spectrum in seven simple snorers and 10 obstructive sleep apnoea (OSA) patients. There is a significant negative correlation (Spearman rank order correlation: $\mathrm{r}=-0.61 ; \mathrm{p}<0.0089$ ). small amounts of Stages 3 and 4 non-REM sleep. REM sleep was better preserved.

Spectral analysis of snoring showed the existence of two different patterns. The first pattern was characterized by the presence of a fundamental frequency and several harmonics through a broad frequency band (fig. $1)$. The second pattern was characterized by the clear predominance of sound energy scattered on a narrower band of frequencies, but without clearly identified harmonics (fig. 2).

The seven simple snorers and two of the 10 patients with sleep apnoea showed the first pattern. The two patients with the less severe OSA showed the first pattern and had AHI of, respectively, 13 and 14 events.h $\mathrm{h}^{-1}$ of sleep. The rest of the patients with OSA showed the second pattern of sound spectrum.

Table 3 presents the average frequency indices calculated for both groups, as well as the mean of the individual CoVs for each parameter. There was a significant difference between patients with simple snoring and patients with OSA in peak frequency (table 3). Using a threshold of $150 \mathrm{~Hz}$ for the peak frequency, all but one of the patients with OSA, but only one subject with simple snoring, showed values below this threshold.

All of the other indices showed a tendency for lower values in patients with OSA, but the differences did not reach statistical significance (table 3 ).

Significant negative correlations were found between the number of AHI.h-1 of sleep and the peak and mean frequencies of the power spectrum (fig. 3 and 4).

\section{Discussion}

In this study it was found that patients with simple snoring had a snoring sound spectrum characterized by a fundamental frequency and the presence of harmonics. Snoring analysis was performed on the first breaths following an apnoea in patients with OSA. The pattern decribed for simple snorers was only rarely seen in patients with OSA, who instead seemed to have a spectrum centred around a fundamental frequency without harmonics. In addition, peak frequency was lower in patients with sleep apnoea. A threshold of $150 \mathrm{~Hz}$ best identifid patients with sleep apnoea from simple snorers. Finally, a significant negative correlation was found between the severity of the sleep apnoea syndrome, assessed by the AHI, and the snoring sound spectrum.

Snoring sound is produced by oscillations in the soft palate, pharyngeal walls and epiglottis [8-10]. Snoring is always preceded by flow limitation [9]. Flow limitation has been attributed to the sleep-related decrease in pharyngeal muscle tone. The pharynx may be seen as a collapsible tube. A decrease in the tone of its walls leads to a decrease in its cross-sectional area, with flow limitation followed by high frequency oscillations in the pharyngeal walls. In patients with sleep apnoea, adequate airflow is compromised and is restored with the snoring sound, only after the arousal related reopening of the pharynx. At that time, there are partial and rapid closures and openings of the pharyngeal lumen [11].

Studies on theoretical models have recently confirmed the above hypothesis on snoring production proposed by LiISTRo et al. [11]. 
According to GAvRIELI and co-workers [12, 13], collapsible tubes may show flow limitation and then high frequency oscillations of two different types: the walls of the tube may oscillate without complete collapse; or there may be oscillation with a complete closure in each cycle of oscillation. Oscillation without complete closure corresponds to the sound of a wheeze, whereas oscillation with complete closure would correspond to the sound of snoring. In the present study, two different types of sound spectra were found. The first type, characterized by a fundamental frequency and harmonics, was similar to the spectrum observed during speech, especially emission of vowels [14]. It was characterized by a high intensity peak corresponding to the fundamental frequency, followed by a series of higher frequency peaks with the spectrum occupying a broad band of frequency harmonics, (fig. 1).

The second pattern of sound spectrum was characterized by a low frequency peak, with the rest of the energy of the sound spectrum scattered around a narrower range of frequencies, without clearly identifiable harmonics (fig. 2). This second pattern could correspond to what has been called "relaxation oscillations" or "milking" oscillation tubes [15].

In the present study, differences between peak frequency of both groups (table 3) were observed. Although this result was significant, interpatient variability was high due to characteristics of peak frequency. Mean frequency was higher in snoring patients but not statistically significant.

The present data show substantial differences with respect to the results of PeREz-PADILla et al. [4]. In their study, the peak frequency in patients with simple snoring was lower than in the present study, whereas the peak in patients with OSA was higher. Moreover, in patients with OSA, they also found a residual power at frequencies around 1,000 Hz. Nevertheless, the results of both studies show some similarities: simple snoring was characterized in both studies by a fundamental frequency and the presence of harmonics that rarely exceeded $500 \mathrm{~Hz}$. In patients with obstructive sleep apnoea, harmonics are much more difficult to identify. In the present study, the second broader peak frequency about $1,000 \mathrm{~Hz}$ was not identified.

The main difference between the present study and the study by Perez-Padilla et al. [4], at least as concerns snoring, rests on the method and recording equipment. They placed their microphone on the manubrium sterni, whereas we placed our microphone above the larynx. The filtering effect of the upper airway cavities is quite different from that of the trachea and main bronchi, necessary for the sound to reach a microphone placed on the manubrium sterni. It is, thus, possible that the differences in the recording equipment may be responsible for the quantitative differences between the present results and those of Perez-Padilla et al. [4]. The difference in severity of the OSA between our patients and theirs probably cannot explain the differences between findings. Indeed, in the present study a significant correlation was found between the severity of the OSA syndrome expressed as the AHI and various indices describing the noise spectrum. This correlation implies that, the more severe the OSA, the lower the frequencies describing the spectrum. Therefore, one would expect the patients of Perez-Padilla et al. [4]. who had a more severe OSA syndrome, to have even lower frequencies than the patients in the present sudy.

It is known that in OSA there is oedema of the soft palate [16]. It can be hypothesized that, the higher the AHI the more severe the oedema, with a corresponding increase in the mass of the soft palate. Vibrating structures emit a sound spectrum which is related to their mass, in such a way that, the higher the mass the lower the frequency spectrum of the sound [10]. This could explain the present results both in terms of the lower frequencies in OSA patients compared with patients with simple snoring, and in the negative correlation between the severity of the AHI and the sound spectrum.

Though the general spectra patterns are different in OSA patients and simple snorers, the two patients with the least severe form of OSA showed sound patterns including harmonics. By contrast, only one patient with OSA showed a peak frequency higher than $150 \mathrm{~Hz}$, and only one simple snorer showed frequencies of less than $150 \mathrm{~Hz}$.

An important caveat should be born in mind concerning the present study. In patients with OSA, only the first three breaths after a complete apnoea were analysed. Those three breaths generally take place during the arousal that ends each apnoea. Sleep apnoea is precisely characterized by the occurrence of apnoeas followed by an arousal that allows resumption of flow. Thus, we feel it justified to have performed the present study in this way. If future studies confirm these results, then automated acoustic analysis of snoring could become a useful tool in clinical sleep medicine to separate individuals with apnoea from those with simple snoring.

In conclusion, we have found significant differences in the sound spectrum of snores between patients with simple snoring and patients with obstructive sleep apnoea. These significant differences were observed despite the presence of some overlap between the two groups. Moreover, there was a significant correlation between indices describing the sound spectrum and the severity of the obstructive sleep apnoea syndrome.

\section{References}

1. Lugaresi E, Cirignotta F, Coccagna C, Piana C. Some epidemiological data on snoring and cardiorespiratory disturbances. Sleep 1980; 3: 221-224.

2. Norton PG, Dunn EV. Snoring as a risk factor for disease: an epidemiolocial survey. $B r$ Med $J$ 1985; 291: 630-632.

3. Dalmasso F, Benedetto G, Pogolotti R, Righini G, Spagnolo R. Digital processing of snoring sounds. Eur Respir J 1990; 3: 528-532.

4. Perez-Padilla JR, Slawinski E, Difrancesco LM, Feige RR, Remmers JE, Whitelaw WA. Characteristics of the snoring noise in patients with and without occlusive sleep apnea. Am Rev Respir Dis 1993; 147: 635-644.

5. American Thoracic Society. Standardization of spirometry; 1987 update. Am Rev Respir Dis 1987; 136: $1285-1298$

6. Roca J, Sanchis J, Agusti-Vidal A, et al. Spirometric reference from a Mediterranean population. Bull Eur Physiopathol Respir 1986; 22: 217-224. 
7. Rechtstaffen A, Kales A (eds). A manual of standardized terminology, techniques and scoring system for sleep stages of human subjects. Bethesda, National Institutes of Health, 1968.

8. Grotberg JB, Gavriely N. Flutter in collapsible tubes: a theoretical model of wheezes. J Appl Physiol 1989; 66: 2262-2273.

9. Liistro G, Stanescu DC, Veriter CL, Rodenstein D, Aubert-Tulkens G. Characteristics of snoring in obstructive sleep apnoea patients and healthy snorers during sleep (Abstract). Eur Respir J 1989; 2: 330.

10. Liistro, Stanescu DC, Vertier C. Pattern of simulated snoring is different through mouth and nose. $J$ Appl Physiol 1991; 70: 2736-2741.

11. Liistro G, Stanescu DC, Vertier C, Rodenstein DA, Aubert-Tulkens G. Pattern of snoring in obstructive sleep apnea patients and in heavy snorers. Sleep 1991; 14: 517-525.

12. Gavriely N, Palti Y, Alroy G, Grotberg JB. Measurement and theory of wheezing breath sounds. J Appl Physiol: Respirat Environ Exercise Physiol 1984; 57 (2): 481-482.

13. Gavriely N, Jensen O. Theory and measurements of snores. J Appl Physiol 1993; 74(6): 2828-2837.

14. Fiz JA, Morera J, Abad J, et al. Acoustic analysis of vowel emission in obstructive sleep apnea. Chest 1993; 104: 1093-1096.

15. Cancelli C, Pedley TJ. A seperated-flow model for collapsible-tube ocillations. J Fluid Mech 1985; 157: 375-404.

16. Ryan CF, Lowe AA, Li D, Fleetham JA. Magnetic resonance imaging of the upper airway in obstructive sleep apnoea before and after chronic nasal pressure therapy. Am Rev Respir Dis 1991; 144: 939-944. 